\title{
O SISTEMA LAGUNAR DE MARICÁ: UM ESTUDO DE IMPACTO AMBIENTAL
}

\section{Luis Gabriel Rodrigues Sousa ${ }^{1}$ \\ Antonio Carlos de Miranda ${ }^{2}$ Herika Bastos de Medeiros ${ }^{3}$}

RESUMO: O presente estudo discute o Sistema Lagunar de Maricá, tem como objetivo de identificar a expansão territorial de moradias nas terras secas das lagunas, ocasionadas pela abertura do canal de Ponta Negra. Com isso permitiu baixar o nível das águas lagunares em direção ao mar, sendo reaberta novamente apenas no ano de 2010. Percebemos que houve uma série de intervenções além dos limites da preservação ambiental. A metodologia utilizada apresenta-se como uma pesquisa bibliográfica de caráter descritiva, nesse sentido utilizou-se dados e informações, tais como, mapas por satélites, artigos acadêmicos, jornal, normas, legislações ambientais e as diretrizes das Áreas de Proteção Ambiental.

Palavras- chave: Impacto ambiental. Sistema lagunar de Maricá.

\footnotetext{
${ }^{1}$ Mestre em Ensino da Saúde e do Ambiente (UNIPLI), Prof. da Rede Municipal de São Gonçalo e Rede Estadual do RJ; luisgabrielrs@ibest.com.br

${ }^{2}$ Doutor (UNICAMP); Prof. do Programa de Pós-graduação Stricto Sensu - UNIPLI; mirantam@ig.com.br

${ }^{3}$ Mestre em Ensino da Saúde e do Ambiente (UNIPLI), Prof. da Rede Municipal de São Gonçalo e Rio de Janeiro; herikabastos@yahoo.com.br
} 


\section{1- INTRODUÇÃO}

O presente estudo pretende contribuir para um melhor entendimento do sistema lagunar de Márica, com a análise das alterações ambientais. Essa zona turística fluminense encontra-se a $50 \mathrm{~km}$ da cidade do Município do Rio de Janeiro.

Cabe assinalar que, segundo Leinz e Leonardos, (1977, p 242) lagunas são: "corpos de águas rasas, quietas, separadas do mar por uma barreira e recebe, ao mesmo tempo, águas doces e sedimentos dos rios e águas salgadas do mar, quando da ingressão de marés".

Por sua vez, o sistema lagunar de Maricá possui grande diversidade do ponto de vista botânico. A região abriga várias espécies da fauna ameaçadas de extinção, sendo alvo de proteção ambiental pelo decreto estadual no 7230 de 23/4/1984 (FEEMA, 1988).

Assim, esse estudo discute e analisa os dados, acerca do sistema lagunar de Maricá, com o propósito de melhor entender e caracterizar a veracidade da expansão territorial de moradias, atualmente, nas terras secas das lagunas, como vem sendo denunciado pelos moradores. Nesse sentido, tem como objetivo central identificar o processo de expansão territorial de moradias nas terras secas das lagunas, ocasionadas pela abertura do canal de Ponta Negra.

É importante lembrar que há dez anos a população de Maricá passou a denunciar a especulação imobiliária, com a consequente construções de condomínios em torno das lagoas, cujo nível d'água já estava bastante reduzido, na localidade de Barra de Maricá.

\section{2- DESENVOLVIMENTO}

Inicialmente, é importante lembrar que somente em 2001 foram publicados os dados com as dimensões efetivas da superfície das lagoas, através do uso de recursos modernos 
de medição, pelo projeto PLANÁGUA (fig.1) ${ }^{4}$, cujos resultados foram maiores dos que os obtidos no passado pela carta municipal náutica de 1945.

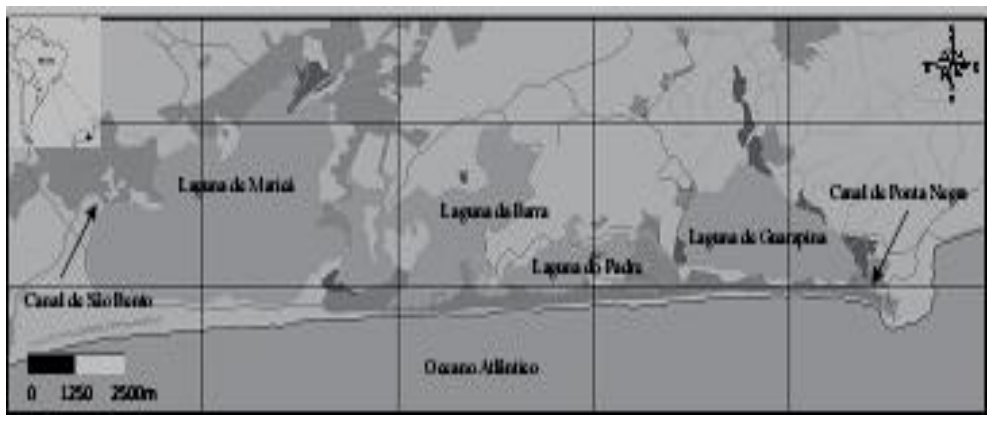

Figura 1 - Sistema Lagunar - Maricá- RJ

Fonte: Site www.marica.com.br

O projeto PLANÁGUA destacou o trecho do litoral, que vem experimentando um rápido processo de urbanização, em torno das lagoas de Maricá (sistema lagunar de MaricáGuarapina), cujas medidas totalizam $37,7 \mathrm{~km}^{2}$, distribuídas da seguinte forma: Maricá $(19,05$ $\left.\mathrm{km}^{2}\right)$; Barra $\left(9,0 \mathrm{~km}^{2}\right)$; Padre $\left(2,7 \mathrm{~km}^{2}\right)$ e Guarapina $\left(6,5 \mathrm{~km}^{2}\right)$, consideradas as medidas oficiais.

O recente estudo de medições dessas bacias hidrográficas fluminenses, diferente da antiga carta náutica, não citou a Laguna de Bocopari, atualmente inexistente e que ficava em frente ao bairro Zacarias em Maricá, onde, como afirmam os pescadores, havia uma grande quantidade de camarões.

Nos anos 50, somente havia as informações da carta municipal náutica da região, nessa época, os governantes executaram a abertura de dois canais artificiais, e então as águas deste sistema lagunar escoavam para o mar. Um desses canais, de forma natural, (fig. 1) fica localizado na restinga, denominado de Canal de São Bento, no trecho limítrofe com a Lagoa da Barra, onde há um local de menor resistência ao fluxo da água do mar, de natureza exclusivamente arenosa e com pequena largura, ele se abria naturalmente ou com ajuda dos pescadores.

\footnotetext{
${ }^{4}$ Em 1999 o governo estadual financiou o projeto PLANÁGUA SEMADS/GTZ, de Cooperação Técnica Brasil Alemanha com objetivo de obter medidas conclusivas sobre as Bacias Hidrográficas e Rios Fluminenses.(SEMADS, 2001).
} 
O outro escoadouro artificial, construído em $1951^{5}$ com auxilio de maquinário, constitui-se do Canal da Ponte Preta (fig. 2), que liga a Lagoa de Guarapina ao mar.

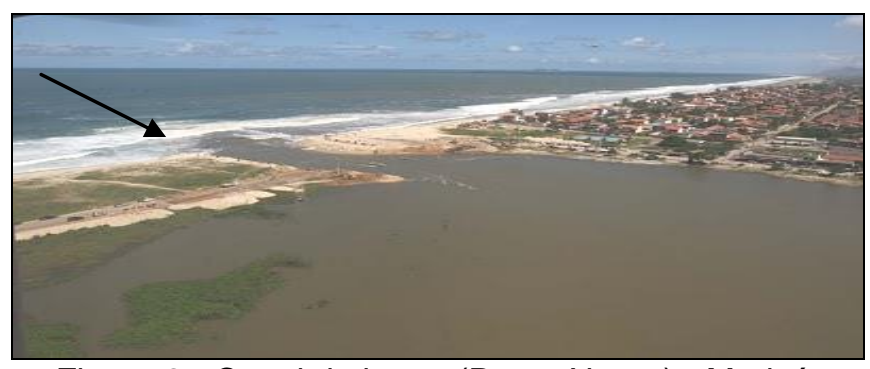

Figura 2 - Canal da lagoa (Ponta Negra) - Maricá

Fonte: http://www.ecodebate.com.br

O canal de Ponta Negra construído com planejamento ambiental permite até hoje, quando aberto, o escoamento das águas das lagoas. Sendo consenso, na literatura sobre o tema, que essa abertura rebaixou ainda mais o nível d'água do sistema lagunar de Maricá como um todo. A obra trouxe drásticas modificações ambientais para o sistema, como a redução da produtividade pesqueira na região de Maricá com a diminuição do espelho d'água.

Acerca dessas alterações, Perrin (1999) afirma: "A região da Lagoa de Maricá encontra-se em bom estado de conservação apesar de parte da restinga já ter sido ocupada por loteamentos". Esse autor, sobre o sistema lagunar de Maricá, descreveu a ocupação de parte da restinga, após o rebaixamento do nível d'água do sistema. Apresenta também os relatos históricos do passado recente, quando o canal de Ponta Negra era aberto e proporcionava um espetáculo pelo turbilhão das águas despejadas no oceano atlântico, permitindo conseqüentemente a comunicação entre águas oceânicas e lacustres, que proporcionava como resultado uma vasta e variada migração de várias espécies ${ }^{6}$.

\footnotetext{
${ }^{5}$ Em 1951, foi construído o canal de Ponta Negra ligando a lagoa de Guarapina ao oceano, em um programa governamental de saneamento para a região das baixadas fluminenses (LUCCOCK, p.435, 1975).

${ }^{6}$ www.you.tube.com. Ver vídeo you tube, abertura do canal Ponta Negra, em 2010, logo depois da enchente que vitimou moradores.
} 
Entre as espécies marinhas, citadas por Perrin, que penetravam na Lagoa estão os camarões (Penaeus brasiliensis), e diversos tipos de peixes, tais como: tainha de corso, a tainha da lagoa, a corvina, paratis, enchovetas, robalos, bagres, entre outros; entravam também no sistema lagunar, os siris e os moluscos.

Temos também o Canal da Costa (fig. 3), com cerca de 5 km de extensão, ligando a Lagoa de Maricá à praia de Itaipuaçu, que funciona mais como uma 'vala' de drenagem dos campos outrora alagadiços.

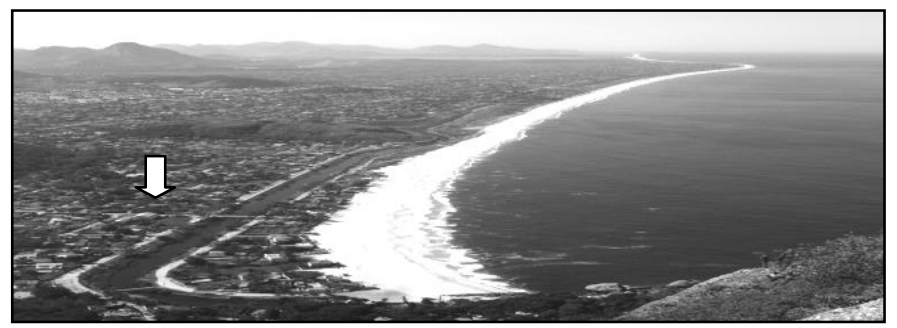

Figura 3. Canal da Costa

Fonte: http://www.ecodebate.com.br

O entendimento dessa dinâmica do sistema lagunar de Maricá é importante para se compreender que as modificações feitas no passado e as atuais geram impacto ambiental naquela localidade.

\section{MATERIAL E MÉTODO}

O presente estudo discute e analisa os dados acerca do sistema lagunar de Maricá, com o propósito de melhor entender e caracterizar a expansão territorial de moradias, atualmente, situadas nas terras secas das lagunas, como vem sendo denunciado pelos moradores.

Pretende-se analisar o uso dos canais do sistema lagunar, visando permitir a migração/entrada de peixes e de outras espécies marinhas na lagoa, além da manutenção da qualidade da água e não para redução do seu volume, com a diminuição da profundidade, visando à expansão de áreas secas voltadas para o loteamento urbano. 
A metodologia apresenta-se como uma pesquisa bibliográfica de caráter descritiva, através de fontes, tais como, mapas por satélites, artigos acadêmicos, jornal, sites (com depoimentos de moradores), normas, legislações ambientais e diretrizes das Áreas de Proteção Ambiental.

\subsection{Das Legislações Ambientais:}

O Brasil tem um dos mais avançados sistemas de proteção ambiental, através das legislações, dentre as quais, a Lei 6.938/81 - Política Nacional do Meio Ambiente e Lei 9.605/98 - Lei dos crimes ambientais.

É importante lembrar que o Decreto Estadual № 7.230 de 23 de abril de 1984 determina que a Região do Sistema Lagunar de Maricá é uma Área de Proteção Ambiental. Por sua vez, a Resolução n.. 001/86 apresenta exigências de estudo e características/ abordagens nos relatório de impacto ambiental em empreendimentos inclusive polêmicos.

As interferências e modificações no sistema lagunar de Maricá, de forma mais efetiva, aconteceram mais intensamente depois do projeto PLANÁGUA divulgar a área de extensão do sistema lagunar cujas medidas totalizaram $37,7 \mathrm{~km}^{2}$, além de outras informações tornando a quase inabitada localidade mais atrativa, para fins turísticos e futuros empreendimentos das imobiliárias.

A pressão por parte desses grandes empreendedores cresceu nos anos seguintes e culminou, em julho de 2007, por meio da CECA (Comissão Estadual de Controle Ambiental do Estado do Rio de Janeiro), na Deliberação № 4.854, de 19 de julho de 2007, tornando parte da restinga, com sua zona seca, isto é, coberta de areia e/ou pedra, permissiva de parcelamento (loteamento). (grifo nosso)

Essa 'Deliberação' deixou a comunidade daquela localidade apreensiva com o provável dano ambiental em uma área sem infra-estrutura de saneamento básico. Cabe lembrar que dois meses após a Deliberação № 4.854, de 19 de julho de 2007, permissiva de ocupação, apresenta-se a Lei no 5.101 , de 04 de outubro de 2007, criando o Instituto 
Estadual do Ambiente (INEA) com a "missão de proteger, conservar e recuperar o meio ambiente para promover o desenvolvimento sustentável".

Pela leitura atenta da Lei № 5.101/07, constatou-se que o seu ponto forte foi a unificação e ampliação da ação de três órgãos ambientais vinculados à Secretaria de Estado do Ambiente (SEA), a saber: a Fundação Estadual de Engenharia e Meio Ambiente (Feema); a Superintendência Estadual de Rios e Lagoas (Serla) e o Instituto Estadual de Florestas (IEF).

\subsection{Das APAs (Decreto no $41.048 / 07$ )}

O Plano de Manejo para a APA, Decreto no 41.048/07, analisado com foco no Sistema Lagunar de Maricá não considerou a Lei do Bioma Mata Atlântica Lei no 11428 de 22 de dezembro de 2006, artigos $2^{\circ}$, $3^{\circ}$ (incisos II, V, VI e VIII); 4으, $5^{\circ}, 6^{\circ}, 7^{\circ}, 9^{\circ}, 10^{\circ}, 11^{\circ}, 13^{\circ}, 2^{\circ}$ e 30ํㅡ, assim como o Código Florestal Lei ํo 4.771 de 15 de setembro de 1965, artigos 1ำ, $2^{\circ}$ e 3ำ e o Plano Nacional de Gerenciamento Costeiro Decreto oㅜ 5.300 de 7 de dezembro de

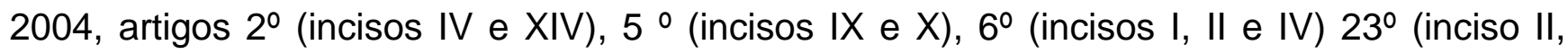
parágrafos $1^{\circ}$ e $\left.2^{\circ}\right)$, que atende à convenção das Nações Unidas para o Direito do Mar da qual o Brasil é signatário.

Os resultados de erros consecutivos originaram mudanças no território do Sistema Lagunar, como se vê a seguir:
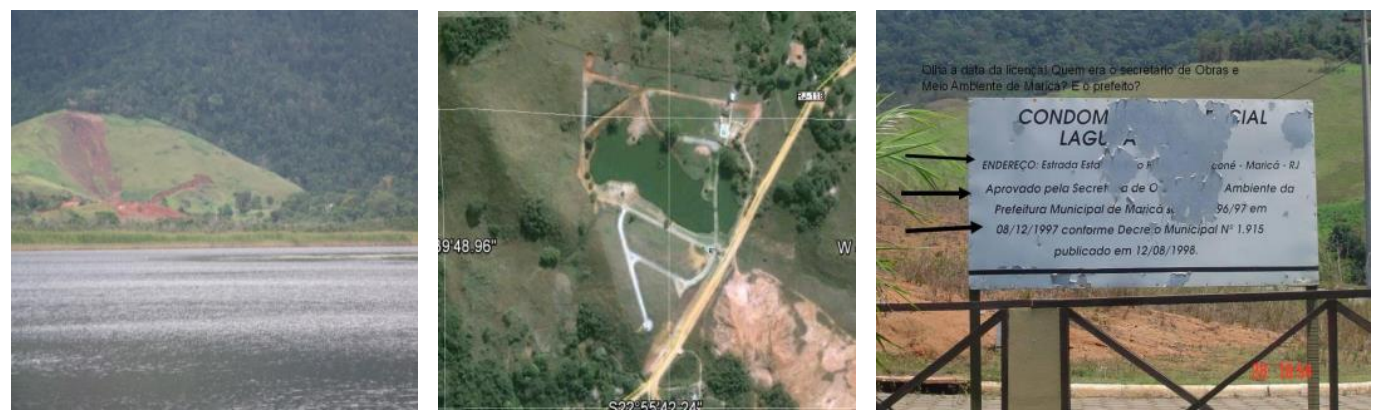

Figura 3- Condomínio em Condomínio

Fonte: Deslizamento do Morro onde um condomínio esta sendo loteado em 2010. 

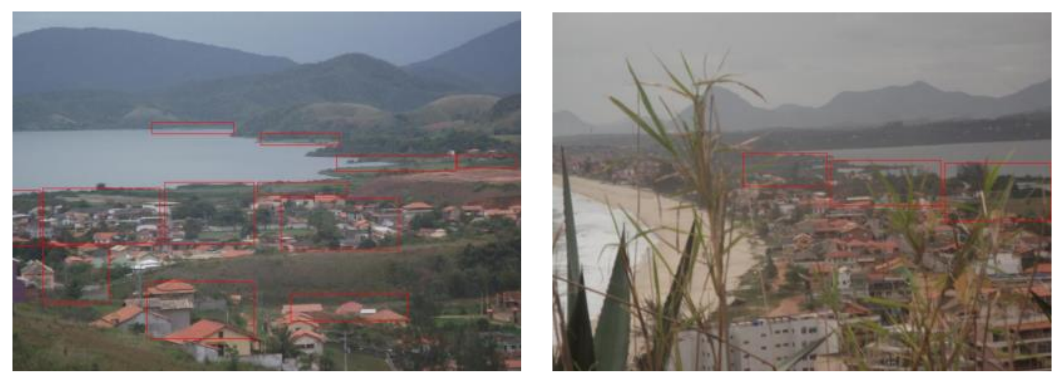

Figura 4- Condomínio Green Park e Construções sobre as lagoas.

Fonte: www.marica.com.br (APEDEMA/RJ-Leste da Baia de Guanabara)

O Plano de Manejo para a APA contêm equívocos graves, quando considerou área de vegetação rasteira, típica do ecossistema daquela localidade, como área degradada, sujeita à ocupação urbana.
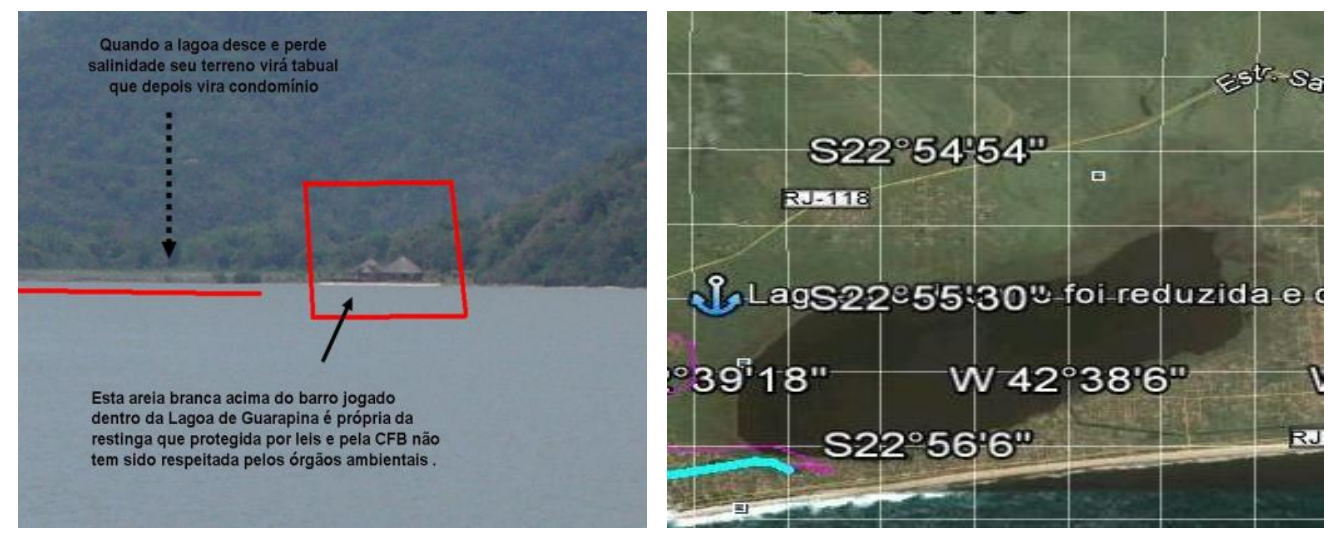

Figura 5- Construções sobre as lagoas depois da diminuição do espelho d'água.

As setas indicam o nível da lagoa no passado em períodos de cheia, e ou, época de chuvas. O Plano de Manejo para a APA definiu as áreas desprovidas de vegetação (possuindo apenas areias e pedras), como em alguns campos de dunas, consideradas áreas degradadas quando, na verdade são características do ecossistema, pertencentes ao cordão arenoso, elemento estrutural da feição geomorfológica. Além de ser um fundamental aporte de areia para a defesa e equilíbrio da costa do estado do Rio de Janeiro e da Região Sudeste.

Nestes últimos anos, a população de Maricá denunciou diversas infrações à sua lei orgânica, e na legislação ambiental vigente, sendo as mais graves citadas pelos moradores através de um site de debate das questões do município: 
Assoreamento das lagoas;

Diminuição do espelho d'água;

Lançamento de aterro clandestino;

Lançamento de esgoto "in Natura" no Complexo Lagunar;

Permissão de construção residencial em faixa marginal de proteção de lagoa (especulação imobiliária, através de um processo de desmembramento de lotes, intenso e desordenado);

Fonte: $\underline{\text { http: } / / w w w . e c o d e b a t e . c o m . b r}$

Vale assinalar que há dez anos a população de Maricá passou a denunciar a especulação imobiliária, com as construções de condomínios em torno das lagoas, cujo nível d'água já estava bastante reduzido, na localidade de Barra de Maricá. Na verdade esse era o motivo real que estava levando as autoridades à ação de manter o Canal de Ponta Negra fechado.

No entanto, identificamos outro motivo de manter o fechamento completo do canal. Visou atender aos moradores da Barra e adjacência (restinga) para terem acesso ao centro de Maricá, já que a ponte de ferro que lá existia, sobre o canal, havia se degradado e desmoronou por falta de conservação. Sem essa ponte, dois importantes bairros de Maricá ficaram mais isolados, como solução a prefeitura construiu uma estrada de terra batida sobre o canal, com grande quantidade de aterro. Esse longo tempo em que o canal não era aberto associado a ausência de chuva na região, se ampliou ainda mais o surgimento de áreas secas em torno das lagoas.

\subsection{Comportamento Físico do Sistema Lagunar de Maricá}

Em 1996, um estudo feito pela Universidade Federal do Rio de Janeiro, já identificava no sistema lagunar de Maricá um contínuo processo de deteriorização do corpo hídrico, sendo um dos principais problemas, na compatibilização de soluções que levem em 
consideração a manutenção de níveis adequados de qualidade de água, sem prejuízo de perda de espelho d'água.

\begin{abstract}
Resultado: Dentre as quatro lagoas, a de Maricá é a que apresenta situação mais preocupante com relação à ocupação urbana de seu entorno, sendo vítima de muitos aterros em sua orla e do lançamento de esgotos em suas águas, situação agravada por sua baixa profundidade, que a qualifica como um frágil ecossistema costeiro. A lagoa do Padre também apresenta grandes modificações em sua forma, resultado de um processo de diminuição do espelho d'água intenso, embora neste caso, a causa seja, principalmente, de origem natural, já que em seu entorno não foi registrado uma ocupação urbana mais significativa. Quanto à lagoa da Barra, tem-se registrado freqüentes ocorrências de mortandade de peixes, devido as obstruções dos canais que as interligam, que dificultam o processo de renovação de suas águas, (...) também, que a lagoa Brava, pequeno corpo d'água próximo ao canal da Costa, desapareceu, tendo sido transformada numa área de alagadiço, onde a especulação imobiliária tem avançado rapidamente (UFRJ, 1996).
\end{abstract}

Segundo Barroso et al (2001) "A construção da ligação com o mar acarretou profundas alterações para o Sistema, como a queda na produtividade pesqueira, redução do espelho d'água, queda na qualidade da água, mortandade de peixes, (...) além disso o sistema sofre com a falta de estrutura de saneamento básico".(IBAMA)

Em 2008, após dez anos do relatório da UFRJ, um relatório sobre o Sistema Lagunar de Maricá foi publicado na Revista Brasileira de Geociências, apontando o rápido processo de urbanização em Maricá, no trecho do litoral, nem sempre se respeitando a dinâmica característica do ambiente (...) com a construção de obras de engenharia dentro dos limites da praia e das lagoas e a conseqüente destruição das mesmas, (...) considera-se preocupante a situação dessa região (...).

Em 2009, uma denúncia ao órgão municipal de Maricá sobre a degradação ambiental das lagoas fluminenses gerou a seguinte explicação, "(...) "sobretudo: em decorrência do lançamento de esgotos sem tratamento, do expressivo aporte de sedimentos, da reduzida renovação e circulação das águas e da invasão do espelho d'água e da FMP (Faixa Marginal de Proteção) com aterros e edificações." (Revista Gente \& Praias - artigo: O que de bom acontece na Região dos Lagos, 2009).

Cruz (2010) elenca em seus estudos de 'Conclusão sobre o Comportamento do Sistema Lagunar de Maricá': "Comparando as fontes de informação, conclui-se que as 
lagoas sofreram enormes reduções do espelho d'água, principalmente a lagoa do Padre, de meados dos anos noventa do século passado até hoje".

Observa-se pelos laudos apresentados por instituições de pesquisa que as mudanças físicas no Sistema Lagunar de Maricá recaem exclusivamente na questão da falta de uma gestão ambiental naquela localidade por meios de agentes públicos, principalmente com relação ao controle das ocupações territoriais das áreas lagunares.

Por outro lado, em abril de $2010^{7}$, o município de Maricá sofreu fortes chuvas e as inundações resultaram em 2.872 pessoas desalojadas, outras 248 desabrigadas na cidade de Maricá, além de três mortes. Em caráter de urgência, justificada pela não existência de comportas para controle de vazão das águas das lagoas foi feita a abertura fora de época do canal da Barra (Ponta Negra).

'Culpar a lagoa pela tragédia ou usá-la como válvula de escape é uma injustiça'! Assim pensam os moradores, que após o acidente causado por um acúmulo das chuvas em Maricá, levou a abertura do canal fechado há mais de dez anos. A população formada por moradores mais antigos de Maricá afirmam: - A lagoa não estava transbordando, e sim, retornou ao seu nível normal de anos passados!

Defendem os moradores que a ação governamental que mantinha o Canal de Ponta Negra fechado culminou em alterações no volume das águas e interferiu também sobre a morfologia social da região, beneficiando pequenos assentamentos imobiliários em localidades da restinga que ficaram secas, adjacentes ao Canal.

A população faz uma declaração importante aos jornais da região depois da tragédia: "Há trinta anos, o nível da lagoa era muito mais elevado do que hoje se vê na enchente e não era culpa das chuvas, como querem fazer crer".

Para eles, a abertura do canal fora de época para salvar condomínios alagados, não foi ganho, e sim grandes perdas, pois prejudicou a criação e o desenvolvimento de várias espécies de peixes.

\footnotetext{
${ }^{7}$ A prefeitura de Maricá e o Inea decidiram abrir o canal entre a lagoa e a praia da Barra de Maricá nas primeiras horas da manhã desta sexta-feira, para escoar a água da lagoa que transborda em diversos pontos da cidade. Segundo o superintendente regional do Inea, Stefan Gomes, avaliações técnicas, inclusive com apoio de topógrafos do Comperj monitoram as condições para a realização do trabalho..
} 


\section{CONSIDERAÇÕES FINAIS}

Urge discutir as graves questões ambientais que estão presentes no sistema lagunar de Maricá. Desde os pequenos empreendimentos ali já instalados em forma de condomínio que avançam nas áreas secas da restinga, até aos grandes investimentos que já estão sendo previstos. Acrescente-se ainda a implementação de um projeto para aproveitamento turístico-náutico das lagoas. Portanto, cresce a necessidade de um controle ambiental eficaz pelos órgãos competentes, com a participação dos moradores. Por fim, foi possível identificar que as alterações físicas no Sistema Lagunar de Maricá recaem exclusivamente na falta de uma gestão ambiental e de fiscalização adequada pelos agentes públicos, principalmente em relação ao controle das ocupações territoriais das áreas lagunares.

\section{REFERÊNCIAS}

CRUZ, A. C. COOPE/UFRJ, Análise de Intervenções no Sistema Lagunar de Maricá -RJ, 2010.

BARROSO, L.V; MEDINA R.S.; MOREIRA, P.F; BERNARDES M;C; A pesca nas lagoas costeiras fluminenses. Brasília: IBAMA, 2000.

LUCCOCK, J. Notas sobre o Rio de Janeiro e Partes Meridionais do Brasil. Col. Reconquista do Brasil, Vol. 21. São Paulo: EDUSP; Belo Horizonte: Itatiaia. 1975.435 p

CASTRO FARIA: Pescadores e Pescarias. In.Kant de Lima.

Pescadores de Itaipu. Meio ambiente, conflito e ritual no litoral do Estado do Rio de Janeiro . Niterói: EDUFF, p.21-28, 1997.

LEINZ V. e LEONARDOS O. H. (1977) - "Glossário Geológico" Cia Editora Nacional 242 p Amador E.S.(1986) "Lagunas Fluminenses. Classificação com base na Origem, Idade e o Processos de Evolução" - An. 1, , p. 11-12. Seminário sobre "Conservação de Recursos Pesqueiros". SUDEPE-RJ.

OLIVEIRA, L. \& KRAU, L. Observações Biogeográficas durante a Abertura da Barra da Lagoa de Saquarema .Memórias do Instituto Oswaldo Cruz, Rio de Janeiro: Instituto Oswaldo Cruz. T. 53, fasc. 2, 3 e 4, p.435-453, 1955. 
PERRIN. Physiography and surface formations of the east Fluminense coast, state of Rio de Janeiro, Brazil. In: KNOPPERS, B; BIDONE, E. \& ABRÃO, J.J. (eds) Environmental Geochemistry of Coast Lagoon Systems, Rio de Janeiro, Brazil (Série Geoquímica Ambiental no 6, p.11-23, 1999.

Síntese Informativa por Macrorregião Ambiental. Rio de Janeiro: SEMADS, 2001.

SILVA, A. L. C.; SILVA, M. A. M. \& SANTOS, C. L. Revista Brasileira de Geociências, p.8797, março de 2008.

UFRJ - Universidade Federal do Rio de Janeiro. Departamento de Geografia / IG Departamento de Biologia Marinha / IB llha do Fundão - Rio de Janeiro, RJ, Brasil (1996). 